\title{
DIURNAL AND SEASONAL CARBON DIOXIDE EXCHANGE AND ITS COMPONENTS IN TEMPERATE GRASSLANDS IN THE NETHERLANDS - AN OUTLINE OF THE METHODOLOGY
}

\author{
B.O.M. DIRKS \\ Department of Theoretical Production Ecology, Wageningen Agricultural University, \\ P.O. Box 430, 6700 AK Wageningen, The Netherlands
}

\begin{abstract}
A methodological outline is presented of a study into the diurnal and seasonal cycle of carbon fluxes within grassland ecosystems in the Netherlands in relation to their environment. At experimental sites Lelystad and Zegveld predominantly Lolium perenne $\mathrm{L}$. at a clay and peat soil, respectively - measurements will be made on (1) net $\mathrm{CO}_{2}$ assimilation of the grassland vegetation using infrared gas analysis; (2) carbon distribution within the plant using ${ }^{14} \mathrm{C}$ pulse labeling; and (3) carbon and $\mathrm{CO}_{2}$ fluxes associated with root respiration and soil organic matter decomposition using ${ }^{14} \mathrm{C}$ pulse labeling. At both sites and at experimental site Cabauw additional measurements will be made on total $\mathrm{CO}_{2}$ fluxes between the grassland vegetation and the lower part of the atmospheric boundary layer. For the analysis of the experimental results and generalisation of the relationships between carbon fluxes and environmental and plant factors use will be made of dynamic simulation models of grass growth and soil organic matter dynamics.
\end{abstract}

\section{Introduction}

Long-term records of atmospheric $\mathrm{CO}_{2}$ concentrations indicate a continuous increase from the $18^{\text {th }}$ century onwards (Boden et al, 1991). Since the human perception of atmospheric change in the 1960s, geosphere and biosphere research associated with increasing $\mathrm{CO}_{2}$ levels has increased concurrently.

In the discipline of geosphere research, numerous authors have indicated that atmospheric $\mathrm{CO}_{2}$ could well serve as a climatic factor (Bolin et al, 1986; Houghton $e t$ $a l, 1990)$. Indeed, models of the atmospheric general circulation (GCMs) indicate changes in average global temperature and global temperature patterns induced by changing atmospheric $\mathrm{CO}_{2}$ concentrations (e.g. Gates, 1985; Manabe et al, 1991). Projected changes in the global hydrological cycle are less accurate, at least partly as a result of the disparity between the resolutions of simulated processes and processes determining the hydrological cycle (Gates, 1985). Actual climatic changes have not been detected yet (Coops, 1991), and, despite all theoretical research efforts, are difficult to predict (Goudriaan, 1987, 1992; Kahl et al, 1993). Attempts to validate the projected climatic changes cannot extend beyond comparisons of current climate and GCM performance for those conditions (Gates, 1985).

Water, Air, and Soil Pollution 70: 425-430, 1993.

(C) 1993 Kluwer Academic Publishers. Printed in the Netherlands. 
Whereas under controlled conditions $\mathrm{CO}_{2}$ effects have been well assessed on biospheric subsystems on a small temporal and spatial scale, the effects in field situations have yet to be determined unequivocally (Strain and Thomas, 1992). Detection of effects in the field is difficult because of the large natural heterogeneity (Goudriaan, 1992) and associated complex of feedbacks (Grace, 1991). Conversely, the biosphere displays a major influence on the course of diurnal and annual atmospheric $\mathrm{CO}_{2}$ cycles, with vertical extensions into the atmospheric boundary layer and the full atmospheric column, respectively (Goudriaan, 1987). Sud et al (1990) showed that GCM results with respect to surface fluxes, and therefore the general circulation and hydrological cycle, are modified considerably after accounting for the biosphere.

Carbon sequestering into, and release from, living biomass and soil organic matter constitute long-term biospheric control of atmospheric $\mathrm{CO}_{2}$. The terrestrial biosphere holds substantial amounts of carbon (approximately $500 \mathrm{Gt}$ in living biomass and $1,400 \mathrm{Gt}$ in soil organic matter) as compared to the atmosphere (700 Gt) (Goudriaan, 1987, 1992). Inasmuch as living biomass will reach steady state conditions with respect to carbon sequestration relatively fast, soil organic matter on the other hand may accumulate for prolonged periods of time. Therefore, soil organic matter constitutes a major carbon reservoir (Goudriaan, 1987, 1992) - a carbon sink or source, in case of a net sequestration or release, respectively.

Goudriaan (1992) distinguished between six major vegetation types for the world. In this subdivision, grasslands in 1980 covered 1,800 Mha of Earth's surface, although a part of the sparsely vegetated surface of 3,000 Mha could equally be denominated as more broadly defined grassland. Along with its large surface cover, grassland is characterised by the highest soil carbon density as compared to the other vegetation types.

Detailed studies on carbon fluxes within the biosphere and between biosphere and atmosphere, either under current or under projected atmospheric and climatic conditions, serve more comprehensive models on the global carbon cycle (Goudriaan, 1987, 1990, 1992). However, to a large extent they seem to have encompassed predominantly forest ecosystems (Wisniewski and Lugo, 1992; this volume). Most efforts in the field of grasslands have been made for the Central Grasslands region in the United States (e.g. Schimel et al, 1990). However, as a result of the still relatively low temporal and spatial resolution most of this research implicitly integrates several relevant processes over time and space. Schimel et al (1990) pointed out substantial intra-regional differences in grassland productivity, most closely related to precipitation patterns. For a mixed grassland ecosystem, Redmann (1978) related measured daily average grass $\mathrm{CO}_{2}$ assimilation to environmental factors using multiple regression analysis. Most detailed studies on $\mathrm{CO}_{2}$ fluxes between grassland and atmosphere were reported for a tallgrass prairie ecosystem (Kim \& Verma, 1990; Verma et al, 1989), encompassing leaf area measurements and eddy correlation flux measurements with a high temporal and spatial resolution. In a concise theoretical study, Kim et al (1992) quantified the components of similar flux 
measurements on a daily basis.

In the following, the methodological outline is presented of a study aiming at elucidation of the carbon fluxes within a grassland ecosystem in relation to its environment. Year-round measurements will be made of the total $\mathrm{CO}_{2}$ flux and its components between grassland and the atmospheric boundary layer at a high temporal resolution. Measurements will be made on two grassland ecosystems in the Netherlands, on two different soil types. The experimental data will be analysed and the relationships between carbon fluxes and environmental and plant factors generalised on the same temporal and spatial resolution as the measurements, applying simulation models for grass growth and soil organic matter dynamics. In the first instance, the generalised relationships between $\mathrm{CO}_{2}$ fluxes and environment and plant will be applied to analyse total $\mathrm{CO}_{2}$ flux measurements at a third grassland ecosystem.

\section{Methodology}

\subsection{EXPERIMENTAL STUDY}

The study encompasses grassland ecosystems at three experimental sites in the Netherlands: Lelystad $\left(52^{\circ} 32^{\prime} \mathrm{N} 5^{\circ} 33^{\prime} \mathrm{E}\right)$, Zegveld (52.07'N $\left.4^{\circ} 52^{\prime} \mathrm{E}\right)$ and Cabauw $\left(51^{\circ} 58^{\prime} \mathrm{N} 4^{\circ} 55^{\prime} \mathrm{E}\right)$. The sites are, depending on the degree of drainage, more or less dominated by perennial ryegrass (Lolium perenne $\mathrm{L}$.). The soils consist of clay, peat, and peat with a top clay layer of $1 \mathrm{~m}$ depth, respectively. Measurements on carbon fluxes will be done with the involvement of the Netherlands Energy Research Foundation (ECN), KEMA Testing Research and Development and Engineering Consultants in the Electric Power Industry (NV KEMA), DLO Institute for Soil Fertility Research (IB-DLO), Royal Netherlands Meteorological Institute (KNMI) and Department of Theoretical Production Ecology, Wageningen Agricultural University (WAU-TPE). The experimental study will last approximately 2 years, and concerns measurements on (1) total $\mathrm{CO}_{2}$ fluxes between the grassland vegetation and the lower part of the atmospheric boundary layer; (2) net $\mathrm{CO}_{2}$ assimilation of the grassland vegetation and carbon distribution within the plant; and (3) carbon and $\mathrm{CO}_{2}$ fluxes associated with root respiration and soil organic matter decomposition. Additional measurements will be made on meteorological parameters and the soil moisture content and soil temperature profiles.

Measurements of the total $\mathrm{CO}_{2}$ flux will be made for the lower 4 to $5 \mathrm{~m}$ of the atmospheric boundary layer.

Measurements on growth and net $\mathrm{CO}_{2}$ assimilation of the grassland vegetation will be made at different temporal and spatial resolutions: $(a)$ instantaneous net $\mathrm{CO}_{2}$ assimilation of approximately $1 \mathrm{~m}^{2}$ of grassland vegetation in two replications, using an infrared gas analyser; (b) growth analyses of approximately $1 \mathrm{~m}^{2}$ of grassland vegetation in several replications at two-week intervals, to determine leaf area, and 
biomass and dry matter of sheath, and green, yellow and dead leaves; and (c) harvest of larger sections of grassland vegetation in several replications at one-week to twoweek intervals, to determine harvestable biomass.

Carbon distribution and redistribution within the plant, in dependence of the plant's physiological development stage and management practices, will be measured by a 1 to 2 hour application of ${ }^{14} \mathrm{C}$ pulse labeling under field conditions.

Carbon and $\mathrm{CO}_{2}$ fluxes associated with the soil subsystem will equally be determined by applying ${ }^{{ }^{14}} \mathrm{C}$ pulse labeling under field conditions. In separate objects ${ }^{14} \mathrm{C}$ labeled $\mathrm{CO}_{2}$ will be applied to the plant and ${ }^{14} \mathrm{C}$-labeled glucose will be injected into the soil. $\mathrm{CO}_{2}$ fluxes from columns of soil will be measured after sealing the soil surface. Subsequent measurements on (a) the distribution of ${ }^{14} \mathrm{C}$ over the different soil organic matter fractions; (b) the respiration from decomposition of shoots, roots and soil organic matter; and (c) the microbial respiration from root exudates, will be made during a period of approximately 2 years.

Table 1 indicates which of the measurements mentioned in the preceding will be made on the different experimental sites by the different institutions.

Table 1. Matrix of measurements to be made at experimental sites Lelystad, Zegveld and Cabauw, indicating the directly responsible institutions.

measurement

experimental location

$\begin{array}{llll} & \text { Lelystad } & \text { Zegveld } & \text { Cabauw } \\ & \text { NV KEMA } & \text { ECN } & \text { ECN/KNMI } \\ \text { total } \mathrm{CO}_{2} \text { flux } & \text { WAU-TPE } & - & - \\ \text { net } \mathrm{CO}_{2} \text { assimilation } & \text { WAU-TPE } & \text { WAU-TPE } & - \\ \text { growth analysis } & \text { experimental } & \text { experimental } & - \\ \text { harvestable biomass } & \text { farm } & \text { farm } & \\ & \text { IB-DLO } & - & - \\ { }^{14} \mathrm{C} \text { pulse labeling } & \text { WAU-TPE } & \text { WAU-TPE } & -\end{array}$

\subsection{THEORETICAL STUDY}

For the analysis of the results from the experimental study and generalization of the relationships between $\mathrm{CO}_{2}$ fluxes and environmental and plant factors use will be made of dynamic simulation models.

A simulation model for grass vegetation growth at a temporal resolution of less than one hour is under development. It is based on the SUCROS crop growth model, originally developed for spring wheat (Van Laar et al, 1992; Spitters et al, 1989). Adaptations of SUCROS for grass growth have been made before, however have proven to be inadequate. Aspects of a simulation model for single plants of 
perennial ryegrass (Van Loo and Lantinga, in prep.) will be used for further adaptations of SUCROS. Summarization of the modeled grass growth processes to a coarser temporal resolution is required for simulation of the cycle of seasonal $\mathrm{CO}_{2}$ exchange.

The principles of a simulation model for the dynamics of soil organic matter are based on a spatial and temporal subdivision, into vertically distributed soil layers and fractions of soil organic matter with different residence times (Parton et al, 1987; Parton et al, 1988; Verberne et al, 1990). To assess the contributions of the different grassland ecosystem components to the diurnal cycle of $\mathrm{CO}_{2}$ exchange, the temporal resolution of the model should be similar to that of the grass growth model.

\section{Acknowledgment}

Drs. J. Goudriaan and C.E. Owensby are acknowledged for their comments on the manuscript.

\section{References}

Boden T.A., Sepanski R.J., and Stoss F.W. (eds): 1991, Trends '91: a compendium of data on global change, Carbon Dioxide Information Analysis Center.

Bolin B., Döös B.R., Jäger J., and Warrick R.A. (eds): 1986, The Greenhouse Effect, Climatic Change, and Ecosystems, Wiley and Sons.

Coops A.J.: 1991, Norsk Geologisk Tidsskrift 71, 179-182.

Gates W.L.: 1985, Climatic Change 7, 267-284.

Goudriaan J.: 1987, Netherlands Journal of Agricultural Science 35, 177-187.

Goudriaan J.: 1990, Atmospheric $\mathrm{CO}_{2}$, global carbon fluxes and the biosphere, in: Rabbinge R., Goudriaan J., Keulen H. van, Penning de Vries F.W.T., and Laar H.H. van (eds). Theoretical Production Ecology: reflections and prospects, Pudoc, pp. $17-40$.

Goudriaan J.: 1992, Journal of Experimental Botany 43, 1111-1119.

Grace J.: 1991, Functional Ecology 5, 192-201.

Houghton J.T., Jenkins G.J., and Ephraums J.J. (eds): 1990, Climate Change - the IPCC Scientific Assessment, Cambridge University Press.

Kahl J.D., Charlevoix D.J., Zaitseva N.A., Schnell R.C., and Serreze M.C.: 1993, Nature 361, 335-337.

Kim J., and Verma S.B.: 1990, Boundary-Layer Meteorology 52, 135-149.

Kim J., Verma S.B., and Clement R.J.: 1992, Journal of Geophysical Research 97, 6057-6063.

Laar H.H. van, Goudriaan J., and Keulen H. van: 1992, Simulation of Crop Growth for Potential and Water-Limited Production Situations (as Applied to Spring Wheat). Centre for Agrobiological Research and Department of Theoretical Production 
Ecology, Wageningen Agricultural University.

Loo E.N. van, and Lantinga E.A.: in prep.

Manabe S., Stouffer R.F., Spelman M.J., and Bryan K.: 1991, Journal of Climate 4, 785-818.

Parton W.J., Schimel D.S., Cole C.V., and Ojima D.S.: 1987, Soil Science Society of America Journal 51, 1173-1179.

Parton W.J., Stewart J.W.B., and Cole C.V.: 1988, Biogeochemistry 5, 109-131.

Redmann R.E.: 1978, Canadian Journal of Botany 56, 1999-2005.

Schimel D.S., Parton W.J., Kittel T.G.F., Ojima D.S., and Cole C.V.: 1990, Climatic Change 17, 13-25.

Spitters C.J.T., Keulen H. van, and Kraalingen D.W.G. van: 1989, A simple and universal crop growth simulator: SUCROS87, in: Rabbinge R., Ward S.A., and Laar H.H. van (eds). Simulation and Systems Management in Crop Protection, Pudoc, pp. 147-181.

Strain B.R., and Thomas R.B.: 1992, Water, Air, and Soil Pollution 64, 45-60.

Sud Y.C., Sellers P.J., Mintz Y., Chou M.D., Walker G.K., and Smith W.E.: 1990, Agricultural and Forest Meteorology 52, 133-180.

Verberne E.L.J., Hassink J., Willigen P. de, Groot J.J.R., and Veen J.A. van: 1990, Netherlands Journal of Agricultural Science 38, 221-238.

Verma S.B., Kim J., and Clement R.J.: 1989, Boundary-Layer Meteorology 46, 53-67. Wisniewski J., and Lugo A.E. (eds): 1992, Natural sinks of $\mathrm{CO}_{2}$ - Palmas del Mar, Puerto Rico, 24-27 February 1992, Kluwer. 